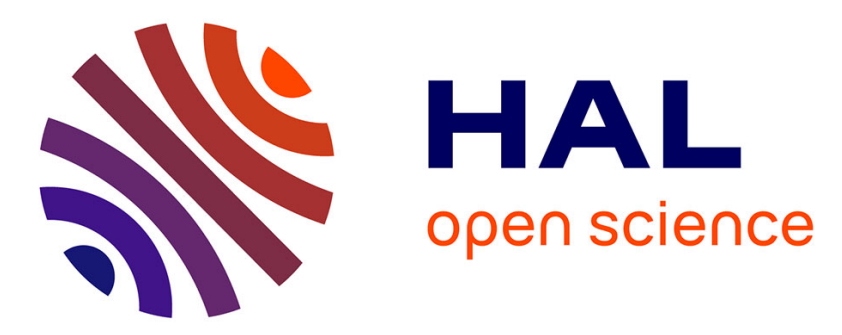

\title{
Older drivers' self-regulation: discrepancy reduction or region of proximal learning?
}

Ladislav Motak, Nathalie Huet, Catherine Gabaude, Jean-Claude Bougeant

\section{To cite this version:}

Ladislav Motak, Nathalie Huet, Catherine Gabaude, Jean-Claude Bougeant. Older drivers' selfregulation: discrepancy reduction or region of proximal learning?. Psychology and Aging, 2012, 27 (4), pp. 1164-1171. 10.1037/a0028650 . hal-00977683

\section{HAL Id: hal-00977683 https://hal.science/hal-00977683}

Submitted on 11 Apr 2014

HAL is a multi-disciplinary open access archive for the deposit and dissemination of scientific research documents, whether they are published or not. The documents may come from teaching and research institutions in France or abroad, or from public or private research centers.
L'archive ouverte pluridisciplinaire HAL, est destinée au dépôt et à la diffusion de documents scientifiques de niveau recherche, publiés ou non, émanant des établissements d'enseignement et de recherche français ou étrangers, des laboratoires publics ou privés. 
MOTAK, Ladislav ; HUET, Nathalie ; GABAUDE, Catherine ; BOUGEANT, Jean-Claude, 2012, Older Drivers' Self-Regulation: Discrepancy Reduction or Region of Proximal

Learning?, Psychology and Aging, 27, 4, AMERICAN PSYCHOLOGICAL ASSOCIATION - APA, pp. 1164-1171, DOI:10.1037/a0028650 
Running Head:

REGION OF PROXIMAL LEARNING IN OLDER DRIVERS

Title:

Older Drivers' Self-Regulation: Discrepancy Reduction or Region of Proximal Learning?

Authors:

Ladislav Moták

Université de Lyon, IFSTTAR - LESCOT

Nathalie Huet

Université de Toulouse-Le-Mirail

Catherine Gabaude

Université de Lyon, IFSTTAR - LESCOT

Jean-Claude Bougeant

Université de Lyon-Lumière 
Author Note

Ladislav Moták and Catherine Gabaude, Université de Lyon, F-69622 Lyon, France, and IFSTTAR, LESCOT, F-69675 Bron, France; Nathalie Huet, CLLE-LTC, Université Toulouse-Le-Mirail, Maison de la Recherche, 31100 Toulouse, France; Jean-Claude Bougeant, EMC, Université Lumière Lyon 2, 69007 Lyon, France.

This article forms part of Ladislav Moták's doctoral dissertation. Some of the data presented here were presented in May 2010, at the meeting of the European Association for Research in Learning and Instruction (EARLI) Special Interest Group 16 Metacognition in Münster, Germany.

This research was supported by the "Territoires, Transports, et Société" research cluster of the Rhône-Alpes region, France, and also by the Psycho Ergo research group (GDR CNRS 3169), France. The authors wish to thank Max Duraz and Daniel Ndiaye for their help in developing the driving scenarios, Elizabeth Portier for her precious language contribution, and two anonymous reviewers for their constructive comments on earlier drafts of this paper.

Correspondence concerning this article should be addressed to Ladislav Moták, whose current address is Université Toulouse Le Mirail, Maison de la Recherche, 5 allées Antonio Machado, 31058 Toulouse, France.E-mail: ladislav.motak@univ-tlse2.fr 


\begin{abstract}
We examined older adults' self-regulation within the region of proximal learning (RPL) framework. Younger and older drivers completed four circuits of increasing difficulty in a driving simulator and were then given a limited amount of time to train for a test. While older drivers chose to train on easier circuits than younger ones, both age groups focused on the easier circuits first, only moving to the more difficult ones later. They were thus equally able to identify their RPL. This framework appears to apply beyond the obvious scope of metamemory and provides a behavioral assessment of self-regulation in driving settings.

Keywords: aging, self-regulation, region of proximal learning, discrepancy reduction, driving
\end{abstract}

Length of manuscript: 279 lines / 3811 words 
Older Drivers' Self-Regulation: Discrepancy Reduction or Region of Proximal Learning?

To what extent can a decline in metacognition be held responsible for older adults' deteriorating cognitive performance (Light, 1991)? Recent studies suggest that monitoring processes are spared by aging (Dunlosky, Baker, Hertzog, \& Rawson, 2006). There is, however, some evidence to suggest that older adults do not spontaneously draw on their monitoring skills to accurately self-regulate their learning (Hines, Touron, \& Hertzog, 2009).

We argue in this article that evidence for older adults' impaired self-regulation is limited by the fact that it is based solely on the criteria set out in the discrepancy reduction (DR) model of self-regulated learning (Dunlosky \& Hertzog, 1998b). Thus far, any agerelated differences have been regarded as merely indicating impairment of older adults' selfregulation, as only younger adults' self-regulation matches the predictions of the DR model (Hertzog \& Hultsch, 2000). We believe that as well as accounting for age- and experiencerelated differences in the self-regulatory patterns of children and younger adults, the region of proximal learning (RPL; Metcalfe, 2002) framework can also help us to interpret differences in self-regulation between younger and older adults.

While many studies have explored the self-regulation of older drivers (e.g., Baldock, Mathias, McLean, \& Berndt, 2006; Owsley, Stalvey, \& Phillips, 2003), none has referred to the above-mentioned models of self-regulated learning, and vice versa. We argue that the application of self-regulated learning models to driving settings makes it possible both to extend the scope of these models beyond metamemory and to undertake behavioral assessments of older drivers' self-regulation. We begin with a brief overview of the main findings on older adults' self-regulated learning and on self-regulation in older drivers. 
The DR's main assumption is that people initially choose to study the most difficult items available. Researchers have found that harder items are preferentially studied rather than easier ones in at least 35 out of 46 different experimental conditions (Son \& Metcalfe, 2000). Self-regulating one's learning in this way presumably reduces the gap between the perceived and desired levels of learning, or "norm of study" (Nelson, 1996).

The principle idea of the RPL framework is that "there is a region of materials or concepts just beyond the grasp of the learner that is most amenable to learning" (Metcalfe, 2002, p. 350), this region of proximal learning being affected by such variables as the individual's experience, item difficulty, total study time available, and so on. Metcalfe found that study-time allocation shifted from easier to harder items both as the participants' expertise shifted from novice to expert (Metcalfe, 2002) and as the amount of time available increased (Metcalfe \& Kornell, 2005; see also Thiede \& Dunlosky, 1999).

The DR and RPL models can account for the same pattern of self-regulation, though for different reasons. The former predicts that time will be allocated to the most difficult items in every case (Thiede, 1999). According to the latter, however, this pattern is only observed in two very specific cases: if the self-regulating individuals are experts (Metcalfe \& Kornell, 2003), and if there is enough time to allow the less expert individuals to master the easier asyet-unlearned items and then to move on to the more difficult-to-learn ones (Metcalfe, 2002). The RPL framework thus appears to be more comprehensive, as both individual and taskrelated aspects of self-regulation are taken into account.

It is in terms of the DR model that older adults' self-regulation has been deemed to be impaired. Older adults have been reported not only to allocate more of their study time to easier items (Dunlosky \& Connor, 1997), but also to allocate less time to restudy than younger adults (Murphy, Schmitt, Caruso, \& Sanders, 1987). However, we have yet to ascertain the origin and meaning of these age-related differences in self-regulation. 
For a start, monitoring is not adversely affected by aging and cannot therefore account for age-related differences in self-regulation. Gamma correlations between subjective assessments of memory (judgments of learning, JOLs; Nelson \& Narens, 1990) and subsequent recall performances are almost as high for older adults as they are for younger ones (Connor, Dunlosky, \& Hertzog, 1997). Moreover, older adults have been found to be just as capable of basing their JOLs on multiple cues as younger adults (Robinson, Hertzog, \& Dunlosky, 2006).

Furthermore, older adults supposedly have difficulty producing efficient strategies (Dunlosky, Kubat-Silman, \& Hertzog, 2003). However, the age-related differences in selfregulation do not necessarily result from differences in strategy production: older adults successfully comply with instructions to use monitoring when asked to do so (Dunlosky \& Hertzog, 1998a) and may spontaneously undertake self-testing (Dunlosky et al., 2007).

One possible explanation for age-related differences may be that older adults simply adjust the way they self-regulate to match their current cognitive abilities (Dunlosky \& Connor, 1997). It has been suggested that older adults' self-regulation consist of a shift in cognitive processing, with increased reliance on the cognitive resources that are preserved by aging (e.g., attention to discourse context) and less on those that are likely to decline (e.g., working memory; Stine-Morrow, Miller, Gagne, \& Hertzog, 2008). However conscious or unconscious this shift may be, Stine-Morrow and associates' study showed that an individual's self-regulation can only be regarded as accurate when it reflects his or her own cognitive abilities. We therefore argue that older adults' self-regulation may appear accurate on the basis of RPL criteria, as the RPL framework accounts better for individual and taskrelated differences than the DR model does.

Independently of the research on metacognition, there has been considerable interest in older drivers' self-regulation (e.g., Lyman, McGwin, \& Sims, 2001; Rudman, Friedland, 
Chipman, \& Sciortino, 2006; Schlag, 1993). Older drivers are assumed to self-regulate their driving in respect of both their age and their cognitive abilities, insofar as (i) they drive less and less with age (Ball et al., 1998), (ii) those drivers who declare themselves to be less mentally fit also indicate that they drive less often under adverse weather conditions (Kostyniuk \& Molnar, 2008), (iii) the avoidance of night driving is significantly related to overall health and self-ratings for vision and decision-making (Charlton et al., 2006), and (iv) self-efficacy beliefs, regarding processing speed and attentional abilities, are predictive of avoidance of difficult driving situations (Gabaude, Marquié, \& Obriot-Claudel, 2010). Many authors have thus concluded that promoting accurate awareness permits older drivers to avoid risky driving situations and prevents them from avoiding easy situations that they can still cope with (e.g., Anstey, Wood, Lord, \& Walker, 2005; Holland \& Rabbitt, 1992).

Nevertheless, awareness-raising has several limitations, as do the studies it is based on. First, these studies are correlational, and older drivers' avoidance of difficult driving situations may simply be the product of their weaker social engagement (Raitanen, Törmäkangas, Mollenkopf, \& Marcellini, 2003). Second, the correlated data often come from self-reports, thus creating another possible bias in what is really being measured (McGwin, Owsley, \& Ball, 1998). Third, while some preventive measures based on this awarenessraising approach are intended to enhance older drivers' self-regulation (Eby, Molnar, Shope, Vivoda, \& Fordyce, 2003), their effectiveness has yet to be proven (Ker et al., 2005; Nasvadi \& Vavrik, 2007). Finally, there is a marked discrepancy in findings relating to older adults' metacognitive abilities between the metamemory and driving fields, for while the former conclude that older adults have poorer self-regulation, the latter emphasize the need to raise older adults' awareness. This is also why we chose in the present study to apply classic metacognitive paradigms to an as-yet-metacognitively unexplored task, namely driving. 
In our experiment, younger and older participants had to complete four increasingly difficult driving circuits, and were then given a limited amount of time to train for a fictitious test. We argued that older drivers' (but not younger drivers') self-regulation would be incongruent with the predictions of the DR model, while both groups' self-regulation would match the predictions of the RPL framework. We thus expected younger drivers to choose the most difficult circuits and allocate most of their self-paced training time to them (Dunlosky \& Hertzog, 1998b), and predicted that older drivers' RPL would concern easier circuits (Dunlosky \& Connor, 1997; Metcalfe, 2002), as focusing on circuits of the same difficulty as the younger drivers might result in a "labor-in-vain" effect (Nelson \& Leonesio, 1988). Further, we assumed that the circuits would be chosen in order of increasing difficulty during the self-paced training, as the imposed time constraint would impel both age groups to maximize their training gains (Metcalfe \& Kornell, 2005; Son \& Metcalfe, 2000).

Additionally, we felt it was important to rule out the possibility that age-related differences in self-regulation might stem from differences in the quality of the older adults' monitoring (Dunlosky et al., 2003). We therefore asked both age groups to rank the four circuits performed on the simulator from the easiest to the hardest, but also, prior to using the driving simulator, to rank four circuits of increasing difficulty printed on sheets of paper. We predicted that discrepancies between the objective circuit rankings and the subjective ones made by each group would not vary between the less resource-demanding presentation modality (graphical) and the most resource-demanding modality (simulated). In which case, any age-related differences in self-regulation would not be attributable to age-related differences in the online monitoring of difficulty.

\section{Method}

\section{Participants}


Twenty-five younger and 27 older adults took part in the study. All participants scored above 24 on the Mini-Mental State Examination and were in excellent or good physical and mental health. They further stated that they were not taking any central nervous system medication, had been in possession of their driving license for at least three years and drove between 5 and 25 thousand kilometers each year. Unfortunately, owing to simulation sickness, we were only able to retain data for 21 younger adults and 16 older ones for further analyses (Table 1). Participants were treated in accordance with the ethical standards of the American Psychological Association.

\section{Materials}

Four circuits of increasing difficulty. Counterbalanced across participants, these materials were presented to each participant first in graphical, then in simulated form. Their difficulty was manipulated in a cumulative manner, by adding one difficulty at each level. For the purposes of our test, we identified and selected: (a) left turns, a typical high-risk situation for older adults (Mayhew, Simpson, \& Ferguson, 2006); (b) high-density traffic, a situation that older drivers are said to frequently avoid (Kostyniuk \& Molnar, 2008); and (c) driving with restricted visibility (e.g., at night or in fog), also frequently avoided by older drivers (Hakamies-Blomqvist \& Wahlström, 1998). Combining these three difficulties resulted in: (i) the simplest circuit (coefficient 1, for both online monitoring of difficulty and self-regulation), consisting mainly of straight roads with light traffic of approximately 20 cars; (ii) the second easiest circuit (coeff. 2), also consisting only of light traffic, but with four left turns; (iii) a circuit combining the left turns with heavy traffic of approximately 80 cars (coeff. 3); (iv) and the fourth and most difficult circuit (coeff. 4), where we added foggy weather to Circuit 3 to restrict the drivers' visibility. All the driving tasks were performed in a fixed-base driving simulator (environment projected onto three forward screens with a $150^{\circ}$ field of view). 
Assessment of online monitoring of difficulty. A null difference between objective and subjective rankings of circuit difficulty, that is a perfect ranking of $1,2,3,4$, resulted in a discrepancy score of 0 , and was achieved by 17 drivers in the graphical condition and 22 drivers in the simulated condition. In all other cases, the difficulty coefficient of each circuit $(1,2,3$, or 4 , see above) was multiplied by the number of places the circuit had been displaced, the ensuing discrepancy score being the sum of these four products. Thus, a 2, 1, 3, 4 subjective ranking scored $3(1 \times 1+2 \times 1+3 \times 0+4 \times 0)$, while a 4, 1, 3, 2 subjective ranking scored $17(1 \times 1+2 \times 2+3 \times 0+4 \times 3)$. The basic metric properties of this score and all the observed combinations are set out in Appendix A.

Self-regulation. Self-regulation was explored via two training-related variables, (i) perseverance, that is, the amount of time allocated to each circuit, where 0 seconds were allocated to nonselected circuits, and (ii) order of circuit choices, in terms of difficulty.

\section{Procedure}

After arranging four different circuits displayed on A3 sheets in order of supposed difficulty, drivers completed four driving circuits in the simulator and then ranked these, too, from the easiest to the hardest. They were then told that they could train for a forthcoming test (Footnote 1). During this training session, we recorded the order of the participants' choices and their perseverance. The total time allowed was 480 seconds, that is, about one third of the time needed to drive around all four circuits (330 seconds per circuit). The participants were then thanked and debriefed.

\section{Results}

All the dependent variables were submitted to a mixed-design analysis of variance (ANOVA), with age as a between-participants variable and all other independent variables as within-participants factors. We chose $p=.05$ as a significance threshold and partial eta squared as an indicator of effect size. Tukey's HSD was used to conduct post hoc analyses. 
Post hoc $t$-tests were performed on individual comparisons when interaction terms were significant, with Cohen's $d$ as an effect size indicator. Driving performance was operationalized as the mean speed for each of the four circuits, quality of online monitoring by the discrepancy score, and self-regulation by both perseverance and order of choices.

Driving performance. A 2 (age) x 4 (circuit difficulty) mixed ANOVA revealed that older adults drove more slowly than younger adults around all four circuits, $M \mathrm{~s}=44.05 \mathrm{vs}$. $52.88 \mathrm{~km} / \mathrm{h}, F(1,35)=20.16, p<.001, \eta^{2}=.37$. There was also a main effect of circuit difficulty, $F(3,105)=94.20, p<.001, \eta^{2}=.73$, such that both age groups drove more slowly around both the third and fourth circuits $(M \mathrm{~s}=37.52 \mathrm{vs} .45 .09 \mathrm{~km} / \mathrm{h})$ than around the first and the second $(M \mathrm{~s}=57.86$ vs. $53.40 \mathrm{~km} / \mathrm{h}$, all $p \mathrm{~s} \leq .01)$. The lowest speed was recorded for the third circuit, not the fourth one, probably indicating that when their vision is restricted by fog, drivers paradoxically feel safer and drive faster. We did not observe any interaction effect.

Online monitoring of difficulty. A 2 (age) x 2 (display condition) mixed ANOVA revealed no main effect of age or of condition, and no interaction between the two. The two groups' discrepancy scores were almost identical and neither of the groups scored above $M=$ 3.71 (younger drivers in the graphical display condition), indicating a possible floor effect.

Perseverance during the self-paced training. A 2 (age group) x 4 (circuit difficulty) mixed ANOVA revealed no main effect of age or of circuit difficulty. As the interaction term indicates, $F(3,105)=8.48, p<.001, \eta^{2}=.20$ (Fig. 1), older drivers spent more time than younger drivers on the easiest circuit $(M \mathrm{~s}=175.25 \mathrm{~s}$ vs. $60.33 \mathrm{~s})$ and less time than younger drivers on the most difficult circuit $(M \mathrm{~s}=60.31 \mathrm{~s}$ vs. $186.29 \mathrm{~s} ; t \mathrm{~s}(35) \geq 3.35, p \mathrm{~s}<.01, d \mathrm{~s} \geq$ 1.11). The older drivers allocated more of their time to the first and third circuits $(M \mathrm{~s}=$ $175.25 \mathrm{~s}$ and $123.81 \mathrm{~s})$ than to the most difficult one $(M=60.31 \mathrm{~s} ; t \mathrm{~s}(15) \geq 2.51, p \mathrm{~s}=.02, d \mathrm{~s}$ $\geq 0.63)$. Younger drivers allocated less time to the first and second circuits $(M \mathrm{~s}=60.33 \mathrm{~s}$ and $68.38 \mathrm{~s})$ than to the third and fourth ones $(M \mathrm{~s}=165.00 \mathrm{~s}$ and $186.29 \mathrm{~s}$; all $t \mathrm{~s}(20) \geq 2.36, p \mathrm{~s} \leq$ 
$.03, d \mathrm{~s} \geq 0.51)$. Unlike the younger drivers, but in accordance with previous results, older adults' self-regulation thus did not match the predictions of the DR model.

Order of choices during the self-paced training. A 2 (age group) x 2 (order: first vs. second choice) (Footnote 2) mixed ANOVA showed that the first choices of both age groups concerned easier items than the second choices $(M \mathrm{~s}=2.35$ vs. $2.89 ; F(1,35)=6.56, p<.05$, $\left.\eta^{2}=.16\right)$. Furthermore, the older adults' choices concerned easier circuits than the younger drivers' choices $\left(M \mathrm{~s}=2.19\right.$ vs. $\left.2.95 ; F(1,35)=8.90, p<.01, \eta^{2}=.20\right)$. There was no interaction effect. As predicted, both age groups behaved in a strategic manner, concentrating on the easier, more achievable items to start with, only later moving on to harder ones.

\section{Discussion}

In this study, we sought to examine whether the central tenet of older adults' impaired self-regulation would still hold true if we conceptualized it in terms of the RPL framework. Applying the latter in a driving setting would further help us to ascertain whether the RPL framework's validity extends beyond its obvious metamemory scope and whether the assessment of older drivers' self-regulation can be enriched by this behavioral paradigm.

Results confirmed our initial predictions in several respects. The older adults' selfregulation appeared not to match the predictions of the DR model (Hertzog \& Hultsch, 2000). While younger and older adults proved themselves equally capable of monitoring task difficulty (Robinson et al., 2006), the older adults chose to pay attention to easier items than the younger adults did (Dunlosky \& Connor, 1997). However, these results do not per se mean that the older adults' self-regulation was inaccurate: their cognitive and driving performances were poorer, and devoting as much time to the harder circuits as the younger adults did would presumably have led to a labor-in-vain effect (Nelson \& Leonesio, 1988).

We argue that the older drivers focused on their RPL just as much as the younger ones did. During the self-paced training, they moved from easier to harder items, thus maximizing 
their chances of improving their overall driving performance within the allotted time (Son \& Sethi, 2006). Given its consistency with the predictions of the RPL framework, the older adults' self-regulation was appropriate. This is an entirely new finding with respect to recent research on the self-regulatory abilities of older adults (Hines et al., 2009).

Thus far, the RPL framework has been used in respect of tasks such as learning foreign language vocabulary (Metcalfe, 2002) or text recall (Stine-Morrow, Shake, Miles, \& Noh, 2006). For some time, however, it has been apparent that metacognitively guided selfregulation also needs to be investigated in dynamic environment settings (Hoc \& Amalberti, 2007). Ours would appear to be the first study to use the RPL paradigm for this purpose, and we argue that it also sheds light on metacognitive abilities that are not directly linked to learning outcomes. Drivers who reflect on their (declining) abilities reflect on variations in task difficulty, and adjust their behavior accordingly. For instance, when using a new car, they may recognize the need to familiarize themselves with the vehicle before engaging in risky situations, such as driving in adverse weather conditions or during the rush hour. Behaving in an RPL-like manner presumably requires the same metacognitive skills as those cited in the above example, and we can thus infer that individuals who achieve RPL-oriented selfregulation are more likely to drive safely than individuals who do not.

We do not intend to say that older drivers in this study behaved as if they were really driving. RPL paradigm per se is a learning task and the employed instruction definitely invited drivers to improve their driving, that is, to learn how to cope better with the circuits within driving simulator. In fact, this may basically be different from what older drivers' aim is when driving in the real world. Yet, we argue that behaving in an RPL-like manner indicates the existence of those metacognitive abilities (self-assessment, self-regulation and the connection between the two) which might be at least worthwhile when driving in the real 
world. Of course, whether the use of these abilities really occurs and how much these abilities are accessible for older drivers outside laboratory remains as yet unknown.

On the strength of the RPL paradigm, we can also conclude that older adults are quite capable of undertaking self-regulation on the basis of their monitoring, thus challenging the "spared monitoring-impaired control" hypothesis (Hertzog \& Hultsch, 2000; Hines et al., 2009). This conclusion, however, is only a preliminary one, as older adults' self-regulatory efficacy has yet to be fully assessed. It has been assumed that metacognitive guidance of study enhances learning (Thiede, 1999) and that people's performance improves more if they are allowed to choose which items to study (Kornell \& Metcalfe, 2006). We are reasonably confident that the choices our older drivers made led to the greatest possible improvements in their driving performance. Nonetheless, given that some authors assert that the quality of older adults' decision-making differs according to whether it is based on deliberative or intuitive processes (Queen \& Hess, 2010), more research is needed to collect further evidence of older adults' self-regulatory efficacy, and identify the cues underpinning older adults' decisions (Robinson et al., 2006).

It may well be that the older drivers in our study simply tried to avoid the difficulty of driving the simulator. First, we may assume that the older drivers' aim was to avoid as much as possible the simulator sickness phenomena. This hypothesis, however, can be ruled out: while the fourth circuit was the least conducive of simulator sickness - the fact that most of the driving scene was concealed by the fog presumably diminished the perceivable discrepancy between the moving (displayed) and stationary (cabin-related) environments -, it was chosen by older adults only exceptionally.

The second hypothesis is that older drivers targeted the easiest circuits because of difficulties they had to handle the driving simulator. In fact, older adults are argued to have more troubles to adapt within new contexts, indicating that our older drivers might have some 
more difficulties than their younger counterparts to learn how to drive the simulator.

Moreover, while two older drivers had already had experience with the driving simulator prior to our experiment, they still chose to train on the easiest circuits, possibly suggesting that older drivers might require a long period before getting accustomed to the driving simulator.

No data of our study allow for discarding this second hypothesis. Yet, whatever might have been the reasons leading the older adults to focus their self-paced training on the easiest circuits, it still remains that their self-regulation proved accurate. While the chosen circuits' difficulty was lower than that of younger drivers, the older drivers still concentrated on the easier, more achievable items to start with, only later moving on to harder ones. This supports our view that, first, the RPL paradigm is a well-suited one to assess self-regulation in older adults, and second, that these latter are well able of both monitoring and self-regulation, at least when invited to improve their driving in the context of simulated driving. 


\section{References}

Anstey, K.J., Wood, J., Lord, S., \& Walker, J.G. (2005). Cognitive, sensory and physical factors enabling safety in older adults. Clinical Psychology Review, 25, 46-65.

Baldock, M.R.J., Mathias, J.L., McLean, A.J., \& Berndt, A. (2006). Self-regulation of driving and its relationship to driving ability among older adults. Accident Analysis and Prevention, 38, 1038-1045.

Ball, K., Owsley, C., Stalvey, B., Roenker, D.L., Sloane, M.E., \& Graves, M. (1998). Driving avoidance and functional impairment in older drivers. Accident Analysis and Prevention, $30,313-322$.

Charlton, J.L., Oxley, J., Fildes, B., Oxley, P., Newstead, S., Koppel, S., \& O’Hare, M. (2006). Characteristics of older driviers who adopt self-regulatory driving behaviours. Transportation Research Part F, 9, 363-373.

Connor, L.T., Dunlosky, J., \& Hertzog, C. (1997). Age-related differences in absolute but not relative metamemory accuracy. Psychology and Aging, 12, 50-71.

Dunlosky, J., Baker, J. M. C., Rawson, K. A., \& Hertzog, C. (2006). Does aging influence people's metacomprehension? Effects of processing ease on judgments of text learning. Psychology and Aging, 21, 390-400.

Dunlosky, J., Cavallini, E., Roth, H., McGuire, C.L., Vecchi, T., \& Hertzog, C. (2007). Do self-monitoring interventions improve older adult learning? Journals of Gerontology: Series B, 67, Special issue I, 70-76.

Dunlosky, J., \& Connor, L.T. (1997). Age differences in the allocation of study time account for age differences in memory performance. Memory \& Cognition, 25, 691-700.

Dunlosky, J., \& Hertzog, C. (1998a). Aging and deficits in associative memory: What is the role of strategy production? Psychology and Aging, 13, 597-607. 
Dunlosky, J., \& Hertzog, C. (1998b). Training programs to improve learning in later adulthood: Helping older adults educate themselves. In D.J. Hacker, J. Dunlosky, \& A.C. Graesser (Eds.), Metacognition in educational theory and practice (pp. 249-276). Mahwah, NJ: Erlbaum.

Dunlosky, J., Kubat-Silman, A.K., \& Hertzog, C. (2003). Training monitoring skills improves older adults' self-paced associative learning. Psychology and Aging, 18, 340-345.

Eby, D.W., Molnar, L.J., Shope, J.T., Vivoda, J.M., \& Fordyce, T.A. (2003). Improving older driver knowledge and self-awareness through self-assessment: The driving decisions workbook. Journal of Safety Research, 34, 371-381.

Folstein, M.F., Folstein, S.E., \& McHugh, P.R. (1975). 'Mini-mental state'. A practical method for grading the cognitive state of patients for the clinician. Journal of Psychiatric Research, 12, 189-198.

Gabaude, C., Marquié, J.-C., \& Obriot-Claudel, F. (2010). Self-regulatory driving behaviour in the elderly: Relationships with aberrant driving behaviours and perceived abilities. Le Travail Humain, 73, 31-52.

Hakamies-Blomqvist, L., \& Wahlström, B. (1998). Why do older drivers give up driving? Accident Analysis and Prevention, 38, 305-312.

Hertzog, C., \& Hultsch, D.F. (2000). Metacognition in adulthood and old age. In F.I.M. Craik \& T.A. Salthouse (Eds.), The handbook of aging and cognition (2nd ed., pp. 417-466). Mahwah, NJ: Erlbaum.

Hines, J.C., Touron, D.R., \& Hertzog, C. (2009). Metacognitive influences on study time allocation in an associative recognition task: An analysis of adult age differences. Psychology and Aging, 24, 462-475. 
Hoc, J.M., \& Amalberti, R. (2007).Cognitive Control Dynamics for Reaching a Satisficing Performance in Complex Dynamic Situations. Jounal of Cognitive Engineering and Decision Making, 1, 22-55.

Holland, C.A., \& Rabbitt, P.M.A. (1992). People's awareness of their age-related sensory and cognitive deficits and the implications for road safety. Applied Cognitive Psychology, 6, 217-231.

Ker, K., Roberts, I., Collier, T., Beyer, F., Bunn, F., \& Frost, C. (2005). Post-licence driver education for the prevention of road traffic crashes: A systematic review of randomised controlled trials. Accident Analysis and Prevention, 37, 305-313.

Kornell, N., \& Metcalfe, J. (2006). Study efficacy and the region of proximal learning framework. Journal of Experimental Psychology: Learning, Memory, and Cognition, 32, 609-622.

Kostyniuk, L.P., \& Molnar, L.J. (2008). Self-regulatory driving practices among older adults: Health, age and sex effects. Accident Analysis and Prevention, 40, 1576-1580.

Lafont, S., Gabaude, C., Paire-Ficout, L., \& Fabrigoule, C. (2010). Des conducteurs âgés moins dangereux pour les autres: Etude des accidents corporels en France entre 1996 et 2005. Le Travail Humain, 73, 75-92.

Light, L.L. (1991). Memory and aging: Four hypotheses in search of data. Annual Review of Psychology, 42, 333-376.

Lyman, J.M., McGwin, G., \& Sims, R.V. (2001). Factors related to driving difficulty and habits in older drivers. Accident Analysis and Prevention, 33, 413-421.

Mayhew, D.R., Simpson, H.M., \& Ferguson, S.A. (2006). Collisions involving senior drivers: high-risk conditions and locations. Traffic Injury Prevention, 7, 117-124. 
McGwin, G., Owsley, C., \& Ball, K. (1998). Identifying crash involvement among older drivers: Agreement between self-report and state records. Accident Analysis and Prevention, 30, 781-791.

Metcalfe, J. (2002). Is study time allocated selectively to a region of proximal learning? Journal of Experimental Psychology: General, 131, 349-363.

Metcalfe, J., \& Kornell, N. (2003). The dynamics of learning and allocation of study time to a region of proximal learning. Journal of Experimental Psychology: General, 132, 530-542.

Metcalfe, J., \& Kornell, N. (2005). A Region of Proximal Learning model of study time allocation. Journal of Memory and Language, 52, 463-477.

Murphy, M.D., Schmitt, F.A., Caruso, J.C., \& Sanders, R.E. (1987). Metamemory in older adults: The role of monitoring in serial recall. Psychology and Aging, 2, 331-339.

Nasvadi, G.E., \& Vavrik, J. (2007). Crash risk of older drivers after attending a mature driver education program. Accident Analysis and Prevention, 39, 1073-1079.

Nelson, T.O. (1996). Consciousness and metacognition. American Psychologist, 51, 102-116.

Nelson, T.O., \& Leonesio, R.J. (1988). Allocation of self-paced study time and the "labor-invain effect". Journal of Experimental Psychology: Learning, Memory, and Cognition, 14, 676-686.

Nelson, T.O., \& Narens, L. (1990). Metamemory: A theoretical framework and new findings. In G.H. Bower (Ed.), The psychology of learning and motivation: Advances in research and theory (Vol. 26, pp. 125-169). San Diego: Academic Press.

Owsley, C., Stalvey, B.T., \& Phillips, J.M. (2003). The efficacy of an educational intervention in promoting self-regulation among high-risk older drivers. Accident Analysis and Prevention, 35, 393-400.

Queen, T.L., \& Hess, T.M. (2010). Age differences in the effects of conscious and unconscious thought in decision making. Psychology and Aging, 25, 251-261. 
Raitanen, T., Törmäkangas, T., Mollenkopf, H., \& Marcellini, F. (2003). Why do older drivers reduce driving? Findings from three European countries. Transportation Research Part F, 6, 81-95.

Robinson, A.E., Hertzog, C., \& Dunlosky, J. (2006). Aging, encoding fluency, and metacognitive monitoring. Aging, Neuropsychology, and Cognition, 13, 458-478.

Rudman, D.L., Friedland, J., Chipman, M., \& Sciortion, P. (2006). Holding on and letting go: The perspectives of pre-seniors and seniors on driving self-regulation in later life. Canadian Journal on Aging, 25, 65-76.

Schlag, B. (1993). Elderly drivers in Germany--Fitness and driving behavior. Accident Analysis and Prevention, 25, 47-55.

Son, L.K., \& Metcalfe, J. (2000). Metacognitive and control strategies in study-time allocation. Journal of Experimental Psychology: Learning, Memory, and Cognition, 26, 204-221.

Son, L.K., \& Sethi, R. (2006). Metacognitive control and optimal learning. Cognitive Science, $30,1-16$.

Stine-Morrow, E.A.L., Miller, L.M.S., Gagne, D.D., \& Hertzog, C. (2008). Self-regulated reading in adulthood. Psychology and Aging, 23, 131-153.

Stine-Morrow, E.A.L., Shake, M.C., Miles, J.R., \& Noh, S.M. (2006). Adult age differences in the effects of goals on self-regulated sentence processing. Psychology and Aging, 21, 790-803.

Thiede, K.W. (1999). The importance of monitoring and self-regulation during multitrial learning. Psychonomic Bulletin \& Review, 6, 662-667.

Thiede, K.W., \& Dunlosky, J. (1999). Toward a general model of self-regulated study: An analysis of selection of items for study and self-paced study time. Journal of Experimental Psychology: Learning, Memory, and Cognition, 25, 1024-1037. 
Wechsler, D. (1989). Echelle d'Intelligence de Wechsler pour Adultes, Forme Révisée [WAIS-R]. Paris: Centre de Psychologie Appliquée. 


\section{Appendix A}

Basic Metric Properties of the Discrepancy Score, Observed Combinations, and

\section{Supplementary Analyses}

In the graphical display condition, discrepancy scores varied between $\min =0$ (correct ranking $1,2,3,4$ ) and $M A X=15$ points (ranking 3, 1, 4, 2): $M=3.71, S D=3.82$ for younger drivers and $M=2.44, S D=3.48$ for older drivers. In the driving simulator condition, discrepancy scores varied between $\min =0$ (correct ranking $1,2,3,4)$ and $M A X=9$ points (ranking 3, 1, 2, 4): $M=1.95, S D=2.77$ for younger drivers and $M=1.94, S D=2.93$ for older drivers. The discrepancy scores were distributed normally across all four experimental conditions. Table A1 indicates all the observed combinations of subjective rankings, together with the attributed discrepancy scores and their frequency across the different conditions.

We performed a further analysis of the discrepancy score, this time calculated as the simple addition of erroneous rankings. For example, ranking the four circuits as 2, 1, 3, 4 resulted in a discrepancy score of 2 points (Circuits 1 and 2 were each one place out), while ranking the four circuits as 3,1,2, 4 resulted in a discrepancy score of 4 points (Circuits 1 and 2 each one place out, Circuit 3 two places out). In these conditions, a 2 (presentation: graphical vs. simulation) x 2 (age: younger vs. older drivers) ANOVA revealed no main effect of age, but a main effect of presentation, $F(1,35)=7.57, p<.01, \eta^{2}=.18$, and most importantly, an interaction between age and presentation, $F(1,35)=7.57, p<.01, \eta^{2}=.18$. While post hoc t-tests did not indicate any age-related differences in either the paper or the driving simulator versions, we found that the younger drivers' rankings improved between the paper version, $M=1.71, S D=1.59$, and the driving simulator version, $M=1.05, S D=1.36$; $t(20)=3.16, p<.01, d=.70$. No such improvement occurred for older drivers, as they obtained equal scores for both the paper and the driving simulator versions $(M \mathrm{~s}=1.13, S D \mathrm{~s}=$ 1.63). In sum, these results indicate that while younger drivers improved their online 
monitoring between the paper and driving simulator versions, no such improvement occurred for older drivers, and most importantly, both age groups achieved similar discrepancy scores, indicating that they did not differ significantly in their online monitoring abilities. 


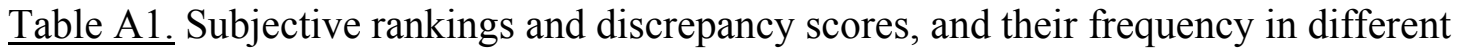
experimental conditions.

\begin{tabular}{|c|c|c|c|c|c|}
\hline \multirow[b]{2}{*}{$\begin{array}{l}\text { Subjective } \\
\text { Ranking }\end{array}$} & \multirow[b]{2}{*}{$\begin{array}{c}\text { Discrepancy } \\
\text { Score }\end{array}$} & \multicolumn{2}{|c|}{$\begin{array}{c}\text { Graphical Display } \\
\text { Frequency }\end{array}$} & \multicolumn{2}{|c|}{$\begin{array}{c}\text { Driving Simulator } \\
\text { Frequency }\end{array}$} \\
\hline & & Younger & Older & Younger & Older \\
\hline $1,2,3,4$ & 0 & 7 & 10 & 12 & 10 \\
\hline $2,1,3,4$ & 3 & 5 & 1 & 6 & 3 \\
\hline $1,3,2,4$ & 5 & 6 & 1 & 0 & 0 \\
\hline $1,2,4,3$ & 7 & 0 & 1 & 1 & 0 \\
\hline $2,3,1,4$ & 7 & 0 & 1 & 1 & 2 \\
\hline $3,2,1,4$ & 8 & 0 & 1 & 0 & 0 \\
\hline $3,1,2,4$ & 9 & 2 & 1 & 1 & 1 \\
\hline $3,1,4,2$ & 15 & 1 & 0 & 0 & 0 \\
\hline
\end{tabular}




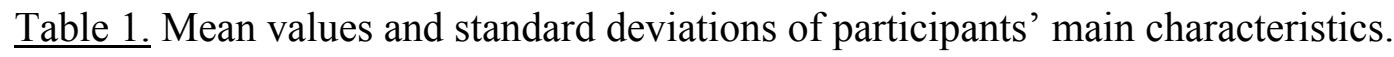

Younger Older

Variable

Mean $\quad$ Mean $\quad S D$

$\begin{array}{lcccc}\text { Male/female ratio } & 13 / 8 & & 11 / 5 & \\ \text { Age (in years) } & 29.67 & 3.38 & 71.75 & 5.31 \\ \text { Driving experience (in } & & & & \\ \text { thousands of km) } & 15.38 & 8.06 & 11.38 & 6.14 \\ \text { Education (in years) } & 14.71 & 1.85 & 13.69 & 2.44 \\ \text { Mental health } & 8.78 & 1.51 & 7.82 & 1.40 \\ \text { Physical health } & 8.23 & 2.29 & 7.56 & 2.06 \\ \text { Mini-Mental State } & 29.11 & 1.10 & 28.63 & 1.26 \\ \text { Digit-Symbol Substitution } & 58.10 & 8.30 & 41.38 & 7.96\end{array}$

Note. Both physical and mental health were subjectively rated on 10 -cm scales ranging from "very bad" $(0 \mathrm{~cm})$ to "excellent" $(10 \mathrm{~cm})$. The Digit-Symbol Substitution Test (range 1-133) was drawn from the Wechsler Adult Intelligence Scale $\left(3^{\text {rd }}\right.$ ed., French translation, Wechsler, 1987). The Mini-Mental State Examination (range 0-30) is a French translation of the original Mini-Mental State (Folstein, Folstein, \& McHugh, 1975). 
$\square$ Circuit 1 国 Circuit 2 国 Circuit 3 a Circuit 4

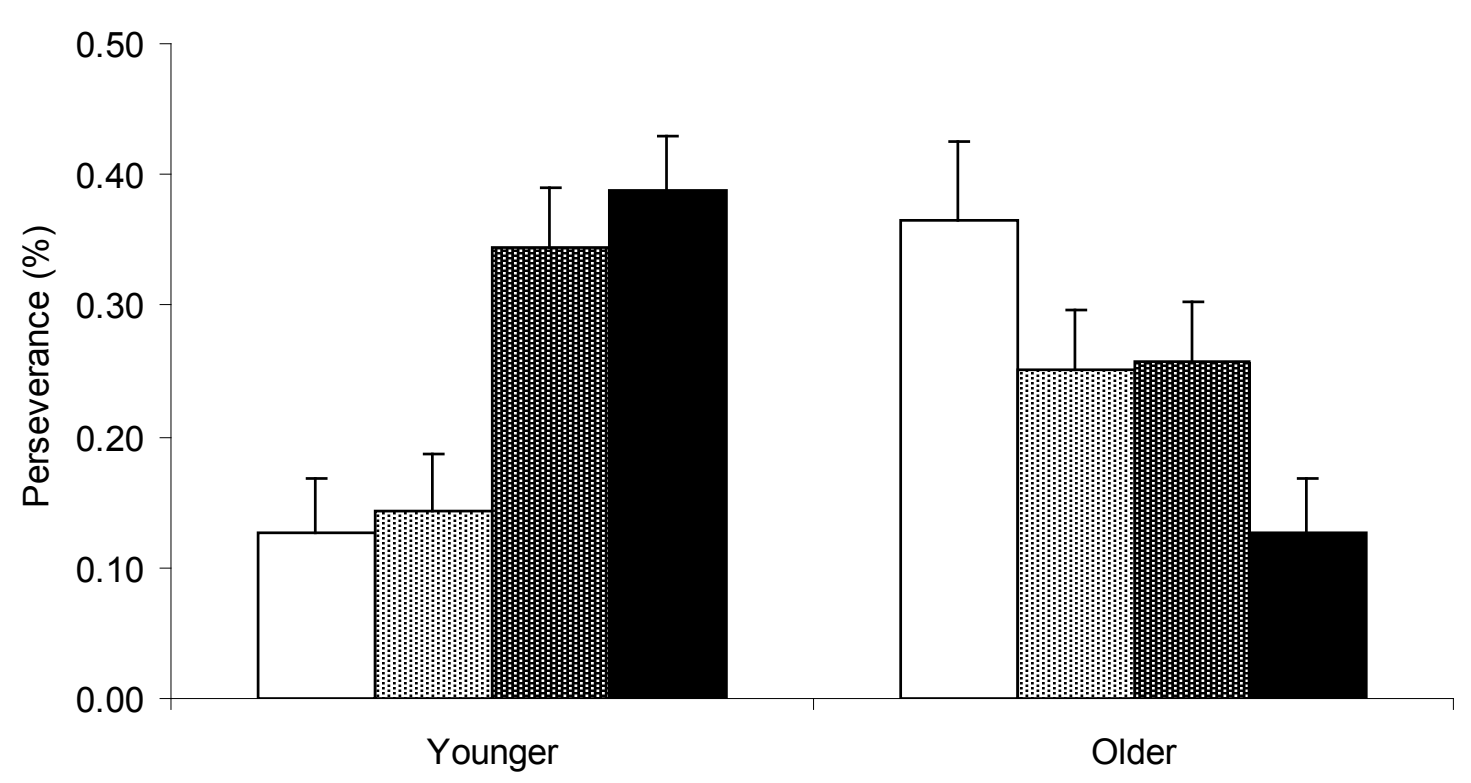

Figure 1. Perseverance of younger and older drivers during the self-paced training for the different circuits. Error bars indicate the standard error of the mean. 


\section{Footnote 1}

The exact wording was as follows: "In the previous circuits, your driving was more or less confident, more or less safe. We are now going to allow you an eight-minute practice session, where you can train yourself to drive as safely as possible for the next test. Hence, you can go back over exactly the same circuits. Of course, you are free regarding the choice of circuits, the order in which you practice them, and the time you spend on each of them, but you must respect the 8-minute time limit. Inside the simulator, on your right, you can see a timer indicating the amount of time left before the end of your training session. If you wish to change from one circuit to another at any time, just say 'stop' and announce the number of the circuit you would like to drive around next. What is the number of the circuit you would like to begin with?" 


\section{Footnote 2}

Out of 21 younger drivers, seven chose to train on three circuits and two chose to train on all four circuits. In the group of older adults, six out of 16 chose to divide their training time between three circuits and three out of 16 chose to divide it between all four circuits. However, we only compared the drivers on their first two choices, as the proportion of drivers who chose to divide their training time between three or more circuits was too low to meet the criteria for statistical analysis. Moreover, for all but one of the drivers who chose to train on three or four circuits, the order of choices revealed the same tendency: either the drivers proceeded from the easiest to the hardest circuit $(1,2,3,4$ or 1, 3, 4), or else they started with a more difficult circuit ( 2 or 3 ), moved on to a more difficult one ( 3 or 4 ) and only then tackled the easiest circuits ( 1 or 2$)$. Both types of training were indicative of self-regulatory behaviors consistent with the predictions of the RPL framework. Only one younger driver behaved in a somewhat contradictory manner, as he started with the second circuit, moved to the first, then to the fourth, and ended up with the third. 